\title{
Decision Support Systems For Strategic Dispute Resolution
}

\author{
Anurag Agarwal, University of South Florida, Sarasota, USA \\ Sridhar Ramamoorti, Kennesaw State University, USA \\ Vaidyanathan Jayaraman, University of Miami, USA
}

\begin{abstract}
Disputes and lawsuits are quite common in business and are often a source of significant liabilities. We conjecture that measurement challenges and lack of adequate analysis tools have greatly inhibited the ability of the General Counsel's offices in selecting the best mode for the resolution (i.e. litigation vs. out-of-court settlement) of business conflicts and disputes. Easily quantified direct costs (e.g., out-of-pocket expenses related to pursuing and defending against litigation) tend to be considered, whereas the more difficult-to-quantify indirect risks and costs (e.g., damaged relationships with customers and potential alliance partners, including reputational harm) which may be quite significant, tend to be ignored. We also hypothesize that the benefits of Alternative Dispute Resolution (ADR) strategies may have been muted because of the failure to assess the real magnitude of not-easily-quantified indirect risks and costs. We propose two Decision Support Systems (DSSs), one for a macro-level analysis and one for a micro-level (i.e. case by case analysis), to alleviate the measurement and analysis problem.

In the proposed DSSs, the underlying decision engine makes use of operations research tools such as decision trees, logic modeling, Monte-Carlo Markov-Chain (MCMC) and fuzzy logic simulations. By providing the means to gather decision-relevant information, especially on difficult-to-measure soft costs, we have attempted to reduce the "decision making risk" for the General Counsel's offices. In the process, we have also furnished some ways to reach more informed assessments to support litigation risk management strategies and decisions.
\end{abstract}

Keywords: decision support systems; decision trees; fuzzy logic; conflict resolution; alternative dispute resolution

\section{INTRODUCTION}

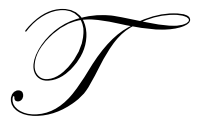

here has been a significant rise in the number of lawsuits or disputes being filed against commercial organizations in recent years. For example, according to a USA Today article [http://www.usatoday.com/news/nation/2001/08/14/walmart-usat.htm], Wal-Mart is sued nearly once every two hours, every day of the year. At any given time, large organizations are trying to resolve hundreds or even thousands of pending lawsuits because the average settlement period often runs into years. According to the same USA Today article, Wal-Mart has over 9,400 open cases. Lawsuit plaintiffs constitute a varied group: customers, business partners, individuals or even governments. These disputes or lawsuits could be of a variety of types, such as patent infringement, breach of contract, product liability, wrongful termination, etc. Overall, battling these lawsuits has become a tremendous burden for the General Counsel's office of small, medium and large companies, occasionally having catastrophic economic consequences while threatening the very survival of the afflicted companies - consider (i) the recent "betting the ranch type" intellectual property litigation against Research in Motion (RIM) risking their largest product offering, the Blackberry and (ii) the Enron case. Decision Support Systems (DSS) are software tools that can help decision makers apply complex analytic methods to a variety of decision making problems such as allocation of scarce resources, risk management, cost/benefit analysis or make-orbuy decisions, amongst others. In this paper we use operations research tools such as decision trees, logic modeling, Monte-Carlo Markov-Chain (MCMC) and fuzzy logic to build a DSS for analyzing commercial disputes/conflicts for their best resolution modes and optimal outcomes. 
While in-court settlements can be quite expensive, in terms of settlement, litigation and other indirect costs, some alternative dispute-resolution (ADR) strategies such as out-of-court settlements, arbitration etc., can be relatively inexpensive. There is a need to better evaluate the optimum mode for handling dispute resolutions (i.e. litigation vs. ADR means). The problem of optimal evaluation of the resolution mode lies in the weak measurements of the costs involved. Although quantifiable litigation and settlement costs of defending against lawsuits tend to be emphasized, organizations incur a multitude of indirect costs, which are often ignored due to the difficulty of measuring them. Such indirect costs may arise from potentially severed relationships with customers or business partners resulting from the litigation process, irreparable reputational damage to the company's brand and adverse regulatory action or loss of key employees. The costs associated with these not-easily-quantified risks can often surpass the out-of-pocket litigation costs, yet are largely ignored by the General Counsel's Office. In this paper, we refer to direct costs as "hard costs" and indirect costs/risks as "soft costs". While hard costs are relatively easily quantifiable, soft costs are not.

One reason for neglecting to quantify the impact of such indirect risks and costs could be the lack of credible and responsive methods, models and tools to analyze and compute a dollar-estimate of such risks. It appears that "easy-to-measure direct costs" frequently drive out "difficult-to-measure indirect risks and costs". This decision-making blind spot occurs despite the very real possibility that the magnitude of indirect costs can exceed the direct costs. Clearly, the "reign of quantity" can sometimes lead decision makers to fall prey to seriously flawed assessments and decisions, particularly when "facing ambiguous threats and having access only to weak signals" (Roberto, Bohmer \& Edmondson, 2006).

In this paper, we seek to provide the means to alleviate this problem through the use of two responsive analytic models. We then demonstrate the implementation of these decision support systems (DSSs) models that can improve litigation-relevant cost/benefit analyses and risk management decisions. Our approach is broad enough to encompass prevention, management and resolution of business disputes by incorporating and combining the ability to quantify, measure and evaluate the costs, benefits, probabilities and risks presented by specific disputes and proceedings, litigation portfolios and business processes.

In addition to ignoring the dire implications of soft costs, we feel the General Counsel Office also undervalues the promise and potential of Alternative Dispute Resolution (ADR) strategies. ADR strategies, such as out-of-court settlements through mediation, negotiation or arbitration can significantly reduce both direct as well as indirect risks and costs. It should be noted that unlike traditional litigation that assume court presence and a courtmanaged process, ADR mechanisms are powerful in that they contain the promise of avoiding litigation altogether, and thus have a valuable, preventative dimension. We conjecture that ADR strategies have not been utilized optimally by General Counsel's Office primarily because of the paucity of credible and responsive models and tools to evaluate a litigation scenario. In this paper, we propose that companies adopt a Strategic Dispute Resolution (SDR) policy to deal with the mounting hard and soft costs of litigation. Such an SDR policy would encourage: (1) an increase in the proportion of new cases to be resolved through various ADR options, (2) acceleration of time to disposition or resolution of cases and (3) consideration of hard as well as soft costs in evaluating new cases.

With respect to the modeling approach, we adopt both a macro-level, aggregate model as well as a microlevel, single litigation case model. The Aggregate Analysis (AA) model considers the entire litigation portfolio of pending cases. The model helps the decision maker estimate, at an aggregate level, the positive impact of implementing the SDR policy. The model provides an estimate of savings in hard as well as soft costs, in effect allowing a macro-level sensitivity analysis for the entire litigation portfolio. This model has been implemented through a decision support system called the AA-DSS, which allows the user to interactively manipulate (using sliding scales), the various input parameters and see the effect of changing parameter values instantly through graphs and spreadsheet analyses.

The second analytic model is called the "Case Analysis" (CA) model. The CA model operates at a microlevel and considers a single case at a time. The CA model helps the decision maker analyze if the case is a good candidate for an ADR option. This model is then implemented as an interactive decision support system called the CA-DSS. In this model, a decision tree which clearly depicts the payoffs for each resolution mode is drawn. Fuzzy logic and Monte-Carlo Markov-Chai (MCMC) simulation techniques are used to translate qualitative estimates of 
win/loss likelihood into quantitative measures. A knowledge base and a database of past cases are integral to this DSS to help the user make better estimates of the monetary values of losses or gains.

In the next section of this paper, we provide a literature review of the tools that have been proposed for dispute resolution in the past. In Section 3, we elaborate on ADR strategies and compare them with litigation. In Section 4, we discuss our AA model in detail and also describe the corresponding AA-DSS. The CA model and the CA-DSS are discussed in Section 5. Section 6 concludes the paper with a summary and a discussion of implications and insights for the General Counsel's Office as well as for business managers.

\section{BACKGROUND AND LITERATURE REVIEW}

Zeleznikow (2000) pointed out that building intelligent decision support systems in discretionary domains will lead to consistent decision-making and increased confidence in the justice system while providing additional support for alternative dispute resolution. Decision makers usually like to exercise their discretion in a judicious manner in order to minimize the level or amount of conflict flowing from their discretion. Brown and Marriott (1999) discuss both ex ante ADR arrangements which usually are made before disputes arise and ex post ADR agreements that are made after disputes arise. There are three reasons why ex ante ADR may be mutually beneficial to the disputing parties (Shavell, 1995). First, ADR may provide superior incentives through greater accuracy of results. For example, if a substandard performance of a contract is correctly assessed by expert arbitrators under ADR, this would raise the willingness of the promise to pay for the contract. Second, ADR may lower the cost of risk or of resolving disputes. Third, ADR may result in improved incentives to either refrain from or engage in disputes. Two entities tend to make ex post ADR agreements after a dispute arises when it can be documented that ADR would produce mutual gains. Such gains can include either a progress towards settlement or reduction of dispute resolution costs. Ex post ADR is assumed to be cheaper than trial especially if it can provide information about what would occur at trial.

Various OR tools have been suggested by researchers to resolve conflicts and disputes that arise in business settings. Pawlak (2005) utilized decision analysis and set theory to resolve conflicts and illustrated the approach by means of a tutorial example of voting analysis in conflict situations. Cheung and Suen (2002) developed a decisionmaking model using the analytical-hierarchy process and multi-attribute utility technique to facilitate a systematic and logical approach in the selection process which in turn seemed to improve objectivity and reduce subjectivity in decision-making. Lootsma (1989) proposed a pairwise comparison method to evaluate possible deals between two parties in conflict wherein both parties resorted to representatives to compare concessions made by the adversary and by his own party. Other tools such as forecasting (Takahashi, 1984), graph theory and decision analysis (Hamouda et al., 2004) and fuzzy logic and game theory (Badredine, 2006) have all been suggested by researchers to resolve disputes.

From an accounting standpoint, Cravens, Oliver \& Ramamoorti (2003) have underscored the reliabilityrelevance trade-off when professional accountants consider intangible or conceptual assets such as corporate reputation. Thus, corporate reputation, because of its inherently unreliable measurement quality, is eschewed in favor of easily measured accounting expenditures. Quality of patient care, a much more difficult-to-measure construct, but one that is highly relevant, is nevertheless "crowded out" by recording highly reliable accounting expenditures such as the upkeep of a hospital building. In general, human cognition, group dynamics, and organizational culture interact in ways that predispose companies to sense and respond to threats less than appropriately (Roberto, Bohmer \& Edmondson, 2006). Further accentuating such suboptimal responses is the lack of decision-relevant information: this is the measurement challenge that we seek to address in this paper through the use of analytic models and knowledge-based DSSs.

In this paper, we use various OR tools such as decision trees, fuzzy logic and MCMC simulation in our knowledge-based DSSs to translate the qualitative estimates of likelihood of win/loss into quantitative measures. The development of such decision support systems offers numerous benefits. First, their use leads to enhanced consistency in decision-making (Zeleznikow, 2000) as well as the means to retain documentation and thus provide justification for specific decisions taken; second, a better community understanding of the domain which would lead to less public and private criticism of judicial decision making; and third, an enhanced support for dispute resolution 
exists since the users of the system will be aware of the likely outcome of litigation and thus be encouraged to avoid the costs and emotional stress of legal proceedings. Most significantly, with respect to "soft costs" we have anecdotal evidence that decision makers (e.g., General Counsels Offices) are unaware of existing DSSs tools and techniques and their potential. Indeed, sophisticated OR tools and DSSs could help tease out the full information set necessary to support a fuller consideration of real-world problems and thus make available decision-relevant information.

\section{ADR VS. LITIGATION}

ADR provides a voluntary alternative to the accepted practice of using the courts to settle civil disputes (http://www.nadr.co.uk/background/contrast.php). The principal forms of ADR are adjudication, arbitration, conciliation and mediation and are valued methods of settling disputes quickly, fairly and cheaply. It has become popular in some quarters, in particular lawyers and mediation service providers, to regard conciliation, negotiation and mediation alone as ADR. For these people a negotiated settlement is an alternative to having a dispute brought to an end by a third party such as an adjudicator, an arbitrator or a judge. This narrow definition ignores the significance of the voluntary aspect of private dispute settlement and the role that is played in all forms of ADR processed by experts and professionals outside the legal profession.

A crucial distinction between litigation and ADR is that whilst many legal practitioners engage in ADR processes, there is no legal or professional requirement for either the ADR practitioner or for party representatives at ADR processes to be legally qualified or to be members of legal professions such as the bar or the law society. Unlike litigation, ADR is private dispute resolution. Many of those who engage in ADR practice are first and foremost experts in particular fields such as architects, builders, civil engineers, mariners, scientists and social workers, albeit with a thorough understanding of ADR processes and some knowledge and understanding of law. Table 1 provides a comparison between Litigation and ADR.

Table 1: Resolving Disputes And Conflicts: Comparing Litigation And ADR Approaches

\begin{tabular}{|l|l|}
\hline Litigation & ADR \\
\hline An intimidating experience for the parties & $\begin{array}{l}\text { Less formal and far more consumer friendly } \\
\text { than attending court hearings. }\end{array}$ \\
\hline Expensive - especially in respect of legal costs and fees. & Less expensive than going to law. \\
\hline $\begin{array}{l}\text { Time consuming with lengthy meetings between the parties and lawyers and } \\
\text { in preparing evidence and discussing strategies. }\end{array}$ & $\begin{array}{l}\text { Less demanding on personal time in respect of } \\
\text { preparation for the process. }\end{array}$ \\
\hline $\begin{array}{l}\text { Long winded and protracted as correspondence flows back and forth between } \\
\text { the parties and their lawyers and in waiting for court hearings. It may take } \\
\text { two or more years to get to court. }\end{array}$ & $\begin{array}{l}\text { Much quicker, enabling parties to get on with } \\
\text { business sooner. }\end{array}$ \\
\hline $\begin{array}{l}\text { Damaging to business interests. Court hearings result in private business } \\
\text { being aired in public, jeopardizing public confidence in ones business affairs. }\end{array}$ & $\begin{array}{l}\text { Conducted in private, protecting business } \\
\text { confidentiality and reputation. }\end{array}$ \\
\hline $\begin{array}{l}\text { Harmful to relationships since the win/lose adversarial aspect of litigation } \\
\text { tends to further alienate the parties making it difficult to maintain business } \\
\text { relations after the dispute has been brought to a judicial conclusion. }\end{array}$ & $\begin{array}{l}\text { Less divisive and assists reconciliation between } \\
\text { the parties. }\end{array}$ \\
\hline $\begin{array}{l}\text { Considered to result in unfair and illogical outcomes which do not reflect } \\
\text { commercial realities. Lawyers and judges are perceived by many as being out } \\
\text { of touch and as having little empathy for the concerns and the needs of clients } \\
\text { and the people who appear before them in court. }\end{array}$ & $\begin{array}{l}\text { Conducted by individuals with commercial and } \\
\text { industrial experience. }\end{array}$ \\
\hline
\end{tabular}

In-house legal experts in large corporate organizations can take part in the entire ADR process without engaging professional lawyers thus cutting costs further, both in terms of time lost through communicating with the professionals and in respect of legal fees and costs. It is also the practical knowledge and understanding of industry and commerce which assures the parties to ADR processes that the people responsible for settling their dispute or assisting them to reach a settlement understand their business and their concerns. It further assures them that the outcome will not be based purely on legal technicalities but will take into account commercial practicalities and technical details which lawyers may not fully comprehend. It is hardly surprising therefore that many people and 
organizations choose to settle their disputes in private, bypassing the judicial system. Conciliation has played a significant role in employer / trade union dispute settlement for almost half a century. Many large employers today operate an internal grievance procedure which helps to keep disputes out of industrial tribunals and the courts. It is attractive for commerce to settle disputes quickly and put an end to uncertainty about future financial commitments. This enables businessmen to settle their affairs and get on with business without having to dip into reserve funds to meet potential liabilities.

In the models and the DSS we propose in this paper, we assume that Strategic Dispute Resolution (SDR) policy is implemented in which (1) a higher proportion of cases are resolved through ADR options, (2) the time for disposition is reduced and (3) hard as well as soft costs are considered. In the next section we discuss the Aggregate Analysis model.

\section{THE AGGREGATE ANALYSIS MODEL}

In the AA-model, we are interested in determining the aggregate or portfolio-level effect (in terms of cost savings), of adopting the SDR policy for resolving cases. The model takes into account savings in both hard as well as soft costs. In simplest terms the AA model is as follows:

CostSavings $_{S D R}=\left(\right.$ HardCostSaving $_{S D R}+$ SoftCostSavings $\left.S_{S D R}\right)$

HardCostSaving $_{S D R}=$ HardCost $_{\text {NoSDR }}-$ HardCost $_{S D R}$

SoftCostSavings $S_{S D R}=$ SoftCost $_{\text {NoSDR }}-$ SoftCost $_{S D R}$

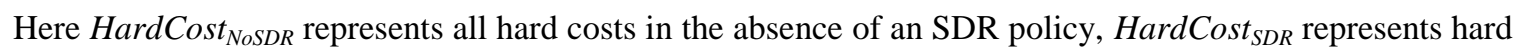
costs in the presence of an SDR policy. The soft cost variables are similarly defined. For the purposes of the AAmodel we are interested in per-year costs. In the following subsections, we will elaborate on the hard and the soft costs.

\subsection{Hard Costs}

As mentioned earlier, we refer to easily quantifiable, direct expenses associated with a litigation case as hard costs. These are variable or overhead costs that can be attributed directly to the prevention, management and resolution of individual conflicts, portfolios of disputes and courses of business conduct or enterprises, such as mergers and joint ventures or performance of specific departments within a company. Direct costs, in our models, include (1) Process costs and (2) Settlement Costs.

HardCost $=$ ProcessCost + SettlementCost

In equation (4), ProcessCost represents the processing or administrative costs and SettlementCost represents the case settlement costs, all incurred on an annual basis.

\section{Process Costs}

Process costs embrace both external and internal costs. External costs are expenditures paid to third party professionals, experts, consultants and other providers engaged in processing a conflict or managing a litigation portfolio, as well as ADR neutrals, settlements and awards to parties resulting from the resolution of a dispute. Internal costs include all internal administrative costs associated with the prevention, management or resolution of the conflict or portfolio. These typically include only the costs of in-house professional services and consultants. An estimate of these costs at an aggregate level can be given by the following function:

ProcessCost $=$ NumCases $*($ AttrnCost + ExpertCost + CnsltCost + IntProfCost + AdmnCost $)$

Here NumCases keeps track of the number of cases handled per year, AttrnCost is the average cost of hiring external attorneys per case, ExpertCost is the average cost of hiring external expert per case, while CnsltCost is the 
average cost of hiring external consultants per case, IntProfCost is the average cost of engaging internal professionals used per case and AdmnCost is the average administrative cost incurred per case.

\section{Settlement Costs}

The settlement cost is quite self explanatory. It is basically the dollar value of the settlement amount as adjudged by the court. We are interested in per year settlement costs.

SettlementCost $=$ NumCases $*$ AvgSettlementCost

We now turn our attention to quantify the soft costs.

\subsection{Soft Costs}

Soft costs, as discussed earlier are the not-easily measurable costs. Soft costs are associated with the risks that accrue during and due to the litigation process. The proposed model identifies each relevant category of business risk and establishes an evaluation criterion that can be applied in order to quantify the financial and economic consequences of each risk. For the purpose of the AA model, we estimate soft costs as follows:

SoftCost $=$ BusRelRisk + AdvPubRisk + RegRisk + InsRisk + CatRisk

In equation (7), BusRelRisk represents the business relationship risk, AdvPubRisk represents the adverse publicity risk, RegRisk is the regulatory risk faced by the company while InsRisk is the risk due to issues surrounding insurance and CatRisk is the risk of catastrophic failure. All these risks are explained in detail in the following paragraphs.

We want to point out that some of these components are not estimable in an absolute way i.e., we cannot provide a dollar value of the regulatory risk for a company. However, we can estimate a change in the dollar-value of risk due to a particular lawsuit. So equation (3) is better expressed as:

SoftCostSavings $_{S D R}=$ SavBusRelRisk + SavAdvPubRisk + SavRegRisk + SavInsRisk + SavCatRisk

In equation (8) all the five components on the right hand side represent savings due to SDR policy. Now we will describe in detail all the five components that make up the Soft costs.

\section{Business Relationship Risk}

Good business relationships engender trust and reduce friction costs while building brand equity and gaining marketplace goodwill and reputation. Management and conduct of dispute resolution frequently presents risks to valuable business relations. These risks can often be measured directly in terms of friction costs resulting from soured relationships that can adversely impact revenues and costs. Significant relationship risks include alliances, employees, suppliers, capital providers, customers, competitors and government regulators. A given dispute or class of disputes can impact one or more of these relationships to an extent that warrants consideration in the development and implementation of a business strategy.

BusRelRisk $=$ CustRisk + SuppRisk + PartnerRisk + EmpRisk

So business relationship risk is further divided into risk that are incurred due to relationship with the customers, suppliers, business partners and employees. In this case, we can quantify the savings that are accrued due to business relationship risk as the difference between business relationship risk with no SDR and with SDR.

SavBusRelRisk $=$ BusRelRisk $_{\text {NoSDR }}+$ BusRelRisk $_{S D R}$ 


\section{$\underline{\text { Customer Relationship Risks }}$}

Dispute management and resolution involves risks of loss of patronage by customers resulting in an adverse customer churn rate from damaged perceptions and relationships. An estimate of such risks is given by the following function:

$$
\begin{aligned}
& \text { CustRisk }=\text { CustRisk }_{K C}+\text { CustRisk }_{N K C} \\
& \text { CustRisk }_{K C}=\text { Num }_{K C} *\left(\text { PercLost }_{K C}-\text { PerCReg }_{K C}\right) *\left(\text { CostRep }_{K C}+\text { CostIncSys }_{K C}+\text { CostAccl }_{K C}+\text { LostProfit }_{K C}\right)
\end{aligned}
$$

Where CustRisk ${ }_{K C}$ and CustRisk ${ }_{N K C}$ represent risk from key and non-key customer relationships, resepectively. Num $_{K C}$ represents the numer of key customers while PercLost ${ }_{K C}$ and PercReg PC $_{K C}$ represents the percentage of key customers lost per year owing to litigation and the percentage of key customers regained, respectively. Further, CostRep ${ }_{K C}$ represents the cost of replacing key customers, CostIncSys ${ }_{K C}$ includes the costs due to incompatibility of systems with new customers, $\operatorname{CostAccl}_{K C}$ represents the acclimatization cost to include new customers and LostProfit $K_{K C}$ is the lost profit in losing a key customer. The estimate for non-key customers is on similar lines to key customers.

\section{Supplier Relationship Risk}

There may also be significant costs associated with increased risks of damage to relationships with suppliers of goods, services and capital. The estimate of supplier relationship risk is given by the following function:

$$
\begin{aligned}
& \text { SuppRisk }=\text { SuppRisk }_{K S}+\text { SuppRisk }_{N K S} \\
& \text { SuppRisk }_{K S}=\text { Num }_{K S} *\left(\text { PercLost }_{K S}-\text { PercReg }_{K S}\right) *\left(\text { CostRep }_{K S}+\text { CostIncSys }_{K S}+\text { CostDownTime }_{K S}\right)
\end{aligned}
$$

In equation (13), Risk $k_{s}$ represents risk from supplier relationships. This consists of risks from key and nonkey supplier relationships. In equation (14), Num $_{k s}$ represents the total number of key suppliers, PercLost $k_{k s}$ includes the percentage of key suppliers lost while PercReg ${ }_{k s}$ includes the percentage of key suppliers regained. CostRep $p_{k s}$ includes the cost of replacing a key supplier, while

CostIncSys $_{k s}$ is the cost due to incompatibility of systems with new key suppliers and CostDownTime ks $_{\text {is }}$ the cost of down time before lost suppliers are replaced.

\section{Business Partner Relationship Risk}

This is the risk associated with losing business opportunities resulting from litigation against or impacting joint-venture alliances and partnerships. We develop the following estimate function for the computation of alliance relationship risk:

$$
\text { PartnerRisk }=\text { Num }_{P} *\left(\text { PercLost }_{P}-\text { PercReg }_{P}\right) *\left(\text { LostProfit }_{P}+\text { LostIntAsset }_{P}+\text { CostSep }_{P}\right)
$$

Here, PartnerRisk represents the risk from partner relationships, while $N_{u m}$ is the total number of partnerships that is a combination of joint venture, mergers \& acquisitions. In addition, PercLost $t_{p}$ is the percentage of partnerships lost while PerReg $g_{p}$ is the percentage of partnerships regained. LostProfit $t_{p}$ is the average amount of lost profits per lost partnerships while LostIntAsset $p_{p}$ represents the average amount of lost intellectual assets portfolio from failed partnerships. Finally, CostSep $p$ is the average partnership failure separation costs.

\section{Employee Relationship Risk}

Management and resolution of disputes risks adverse consequences in relationships with employees. The following function estimates the costs associated with disruptions in human resources:

EmpRisk $=$ Num $_{E} *\left(\right.$ PercLost $\left._{E}\right) *\left(\right.$ CostRep $_{E}+$ CostLostNetwork $_{E}+$ CostTrng $_{P E}+$ CostAdg $\left._{E}\right)$ 
In equation (17), EmpRisk represents the risk from employee relationships, Num $_{E}$ is the total number of employees, while PercLost $t_{E}$ is the employee attrition rate as a percentage of total employees. CostRep is $_{E}$ the costs of replacing employees (measured per employee), while CostLostNetwork ${ }_{E}$ is the cost of lost network of resources, CostTrng $_{E}$ is the cost of training of new employee and $\operatorname{CostAdj}_{\mathrm{E}}$ is the cost associated with time for new employee to adjust.

\section{Adverse Publicity Risk}

The second component of soft cost is the Adverse Publicity risk that the company might attract with unfavorable media and regulatory intervention. An estimate of the savings in aggregate adverse publicity is given by the following:

SavAdvPubRisk $=S G \& A *\left(\operatorname{PerCorr} A d_{\text {NoSDR }}-\operatorname{PerCOrrAd}{ }_{S D R}\right)$

SavAdvPubRisk is the savings in adverse publicity risk, while $S G \& \mathrm{~A}$ represents the selling, general and administrative expenses incurred by the firm on a yearly basis. PerCorrAd $d_{N o S D R}$ and $\operatorname{PerCorrA} d_{S D R}$ is the percentage of SG\&A expenses used for corrective advertising with No-SDR policy and with SDR policy respectively.

The third component of soft cost is the risk that a firm might face due to regulatory issues.

Regulatory Risk

Litigation also presents a risk of adversarial, non-productive relationships with government regulators. The computation of regulatory risk savings is given by the following function:

SavRegRisk $=S G \& A *\left(\right.$ PerRegExp $\left.\operatorname{NoSDR}_{1}-\operatorname{PerRegExp} \operatorname{EDR}_{S}\right)$

In this equation, SavRegRisk is the savings that a firm can accrue due to regulatory risk. This is the product of the selling, general and administrative expenses incurred per year and the difference between the percentage of SG\&A used for regulatory activities with No-SDR policy and with SDR policy.

Insurance Risk

The fourth component of soft cost is the risk of bearing a higher insurance burden that arises from issues such as disputes in coverage and premium costs. The computation of insurance risk savings is given by the following function:

SavInsRisk $=$ InsPrem $*$ PerRedPrem SDR

This savings in risk insurance is a product of the insurance premium and the percentage of reduction in the premium rate due to existence of SDR policies.

The last component of soft costs, discussed next, is the risk that could force the firm to go out of business.

Catastrophic Litigation Outcome Risk

Individual disputes can carry a worst-case scenario of catastrophic risk, disastrous litigation or other outcome that could threaten the firm's ability to continue as a going concern. The computation of catastrophic litigation outcome risk savings is given by the following function:

$$
\text { SavCatRisk }=\text { DelLik }_{S D R} * \text { CatLitExp }
$$

SavCatRisk represents the savings in catastrophic litigation risk and is a product of DelLik $k_{S D R}$, which is the change in the likelihood of catastrophic litigation due to SDR and CatLitExp which represents the exposure due to catastrophic litigation. The exposure could be as high as the market value of the firm or a division or strategic business unit. 
Using equations (1) through (20), the AA model is able to provide aggregate savings in hard as well as soft costs on an annual basis. Of course, estimating each of these costs depends on several parameters which have not been described in the interest of space. The AA-DSS that implements the AA model allows the user to apply the AA model.

\subsection{The AA-DSS}

We implement the AA model as an interactive DSS and call it AA-DSS. As mentioned earlier, the AA model provides an estimate of direct and indirect risks and costs of employing the SDR policy. The assumption is that a company can increase the percentage of cases that are handled through the ADR options vs. litigation. The model estimates the cost savings over a planning period which the user can specify. An interactive DSS that implements the AA model allows the user to enter several input parameters. The user can adjust the values of the parameters using sliding scale control and instantly see the effect of tuning a certain parameter in terms of cost savings through graphic displays. Such an interface allows the user to visually see the sensitive of a parameter.

The most critical and sensitive parameter is the number of new cases going to ADR. Figure 1 gives a screen shot of the hard (or direct) costs for one possible set of input values. We assume, for example, $30 \%$ of new cases going to ADR before SDR while 70\% going to ADR after SDR. The time for disposition is assumed to reduce from 12 months to 10 months. As a comparison, time for disposition for litigation cases is assumed to be 48 months. The user is free to change these numbers and see the resultant savings instantly on the three accompanying graphs. The first graph shows the process and settlement costs before SDR, the second graph shows the same for after SDR while the third shows the savings. In Figure 1, for example, by the end of 8 years, the ADR costs went up from about $\$ 50$ million per month to about $\$ 80$ million per month, but the litigation costs went down from about $\$ 130$ million to about $\$ 60$ million per month. The total cost, therefore, went down from about $\$ 180$ million to $\$ 130$ million per month, a savings of $\$ 50$ million per month or roughly $\$ 600$ million per year in year eight. The number of $\$ 503$ million savings represents an average savings per year over the eight year period. (Note that these are "funny money" inputs, and may therefore appear unusually big).

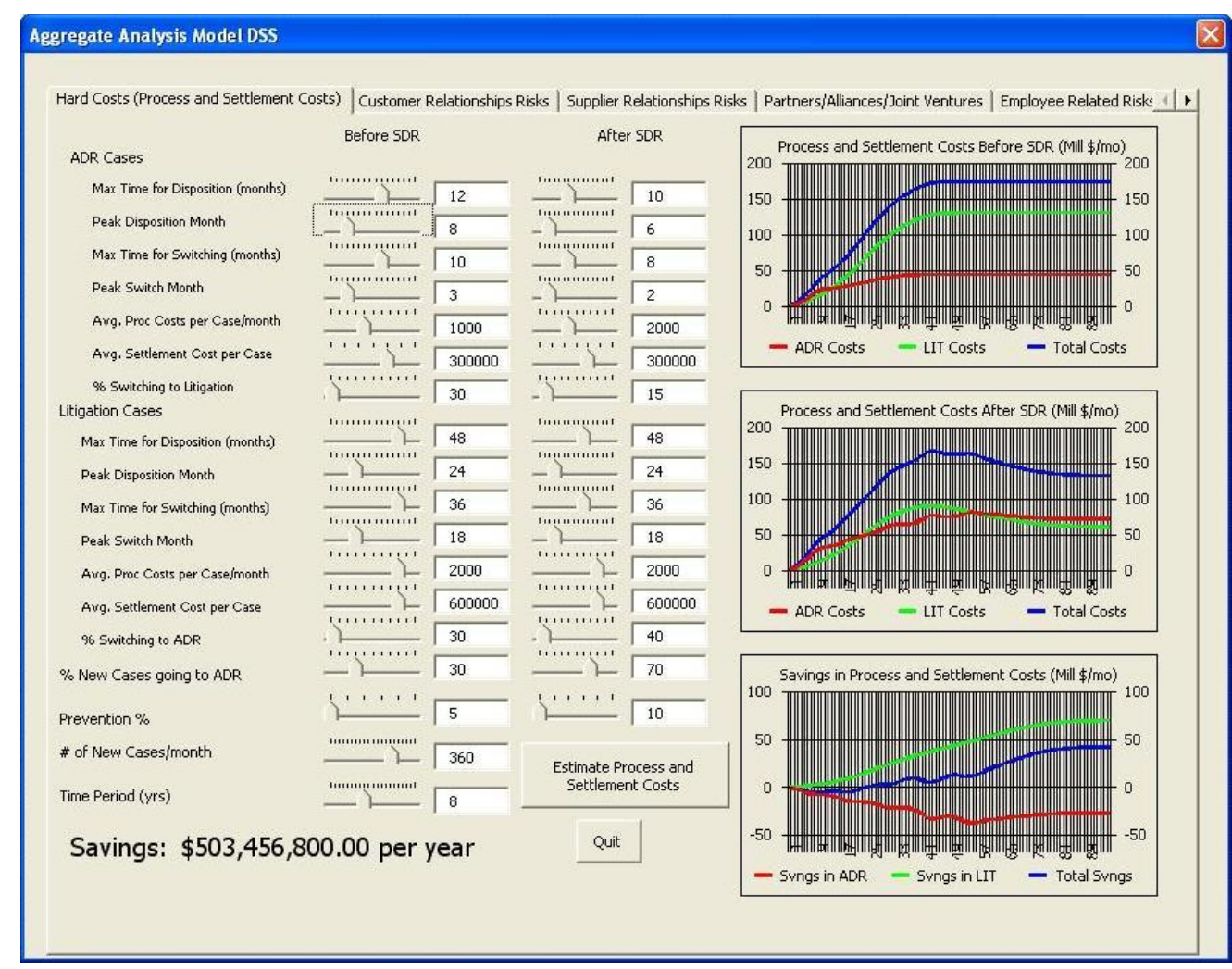

Figure 1: A Screenshot From AA-DSS: Process And Settlement Cost Savings Due To SDR 
Savings from customer relationship risks are shown in a screenshot from the AA-DSS in Figure 2. Note that the customers are classified as key and non-key customers. It is assumed that the percentage of customers we lose as a result of SDR policy reduces from $20 \%$ to 5\%. Again, the user can use the sliding scales to adjust these numbers and visually see the effect on savings in the accompanying graphs. In this example, based on our assumed input, a savings of 44 million per year is projected. Figure 3, shows the savings from supplier relationship risks. We again breakdown the analysis for suppliers into key and non-key suppliers and assume that due to SDR we lose only $5 \%$ suppliers, vs. $10 \%$ with no SDR. Significant savings can be realized as a result of even a small change in the percentage of suppliers not lost. For the numbers assumed in our model, the savings from supplier relationship risk can be as high as an average of 526 million USD per year.

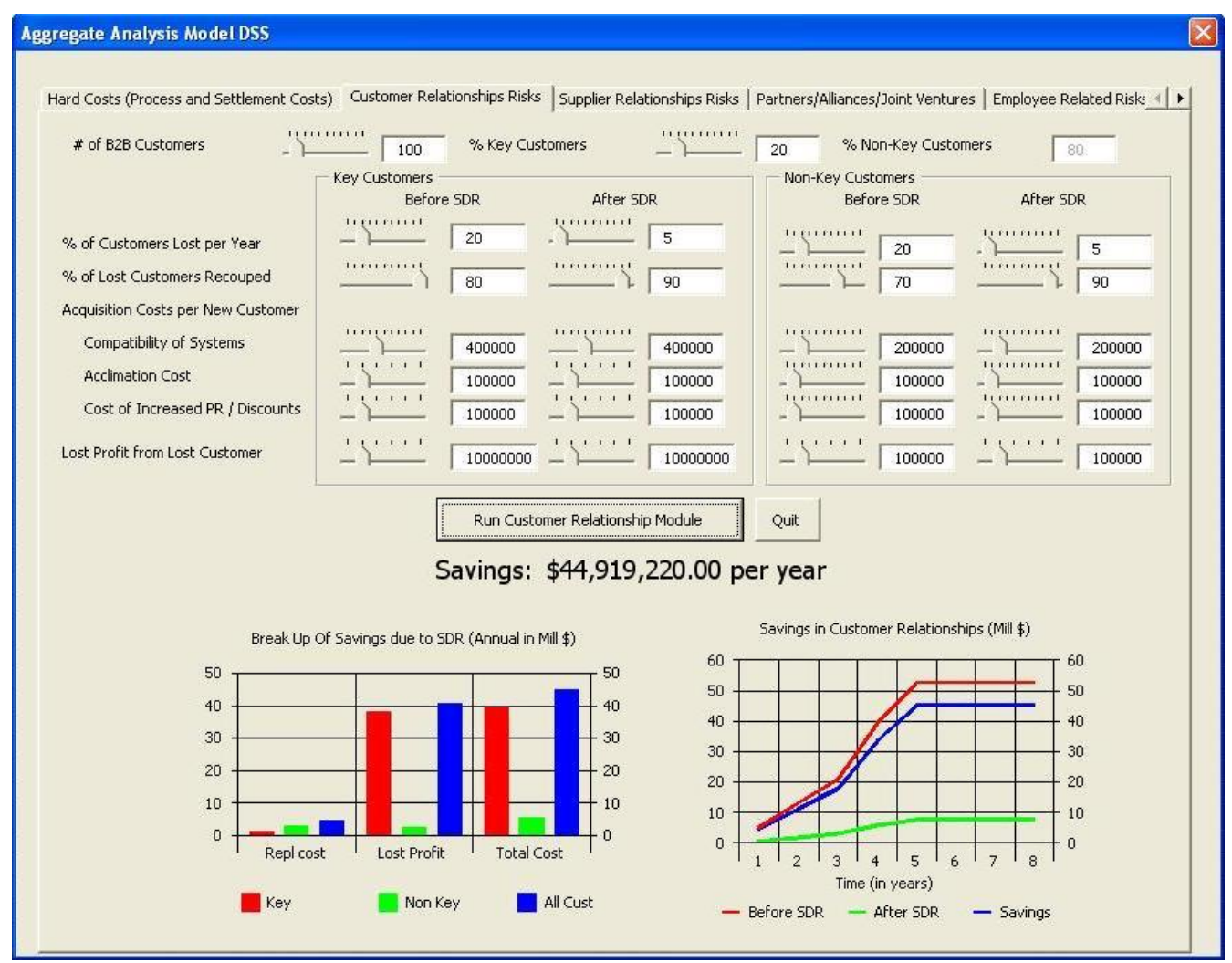

Figure 2: Screenshot From AA-DSS: Savings From Customer Relationship Risks

Figure 4 displays the screenshot from AA-DSS that shows the savings employee-related risks. A potential savings of roughly 19 million per year is projected. Savings from business partner relationship risks are similarly implemented in the AA-DSS. In the interest of saving space we do not show screenshots of every component of cost savings. Figure 5 shows the screenshot that displays the grand summary of all cost savings. We note that based on our numbers, the soft costs amounting to roughly 1.59 billion are about three times as high as the hard costs which amount to about 0.5 billion. Again, we reiterate that these numbers are "funny money" numbers, just to demonstrate the model. The actual numbers will vary significantly, based on user input. 


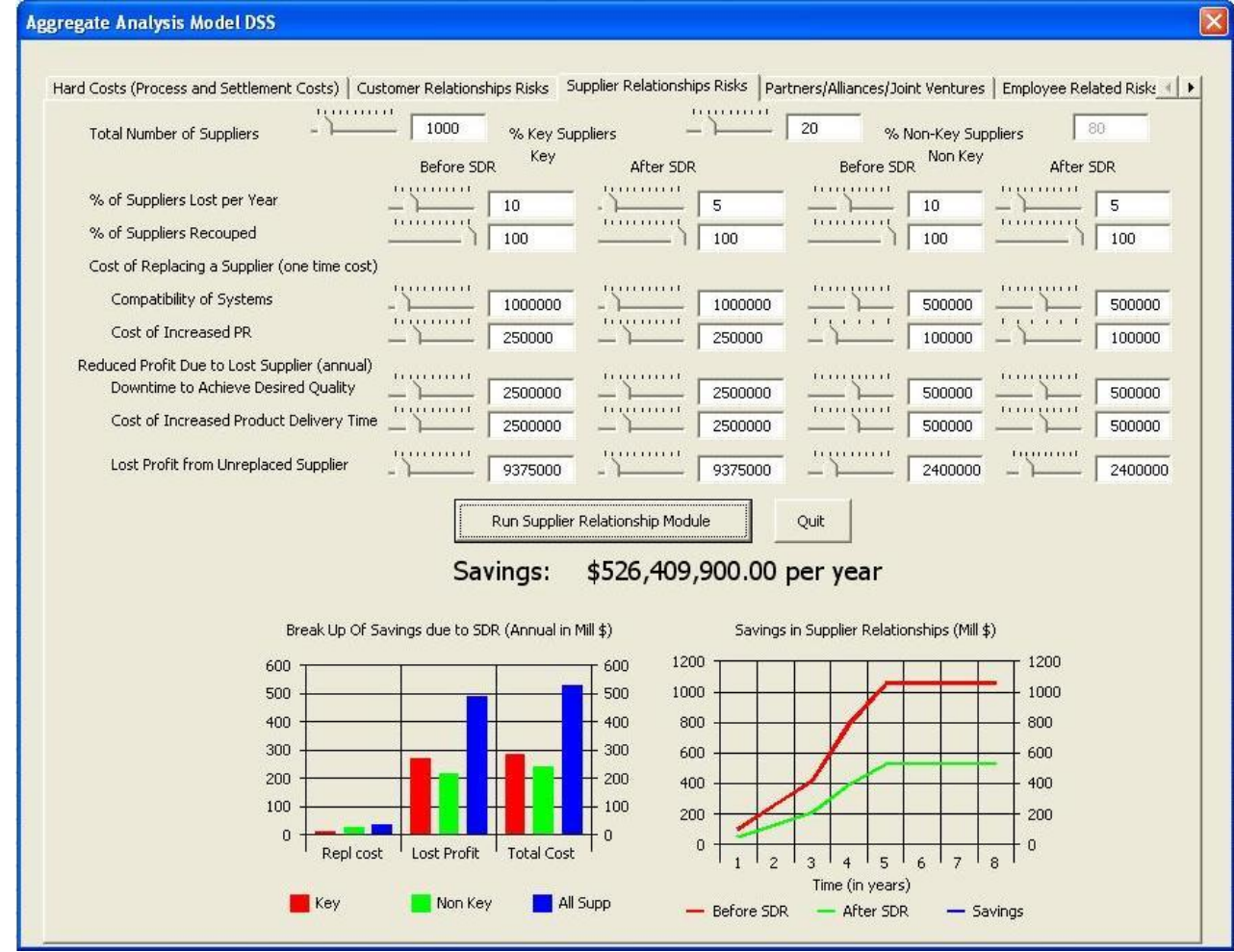

Figure 3: Screenshot From AA-DSS: Savings From Supplier Relationship Risks

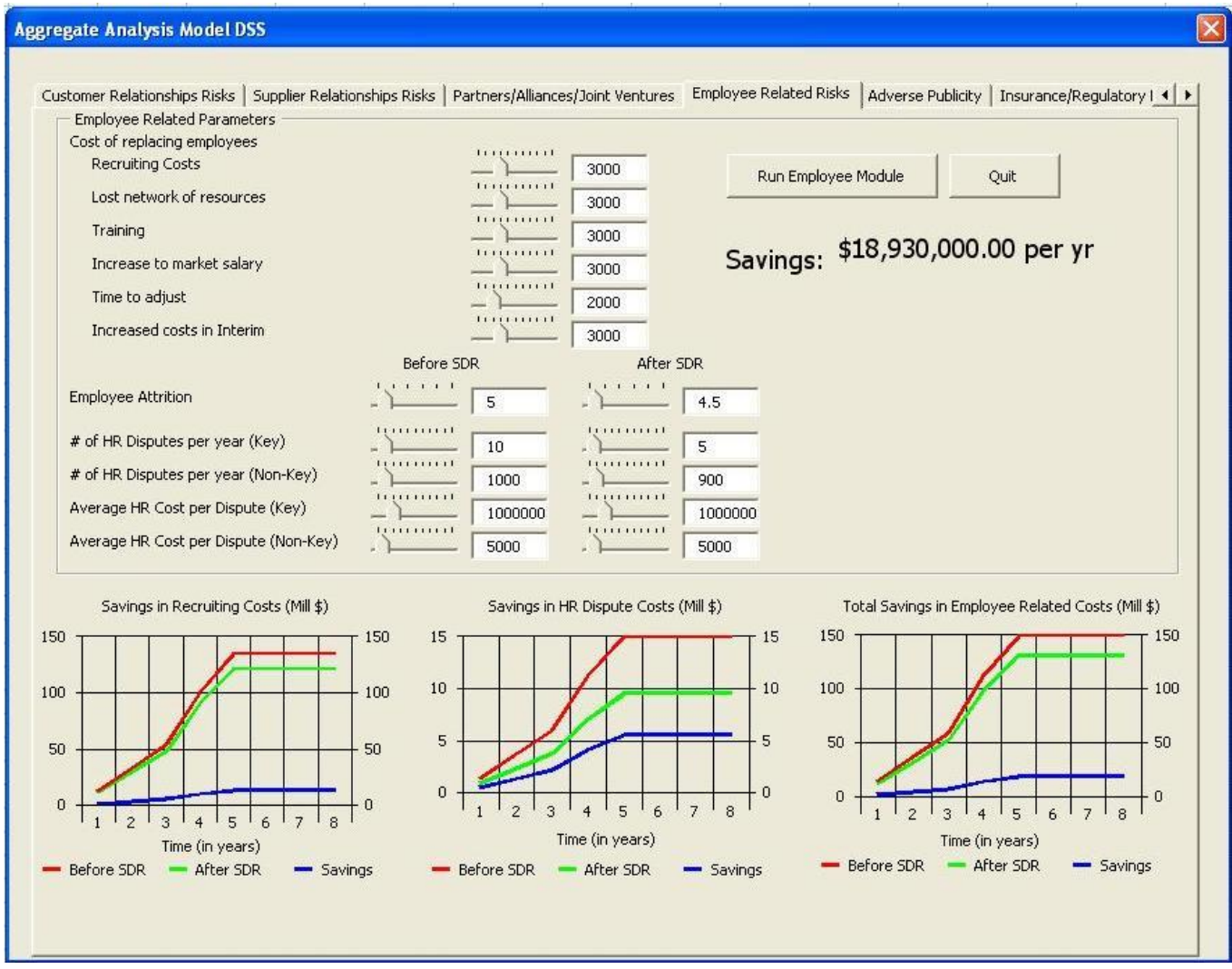

Figure 4: A Screenshot From AA-DSS: Savings From Employee Related Risk Savings 


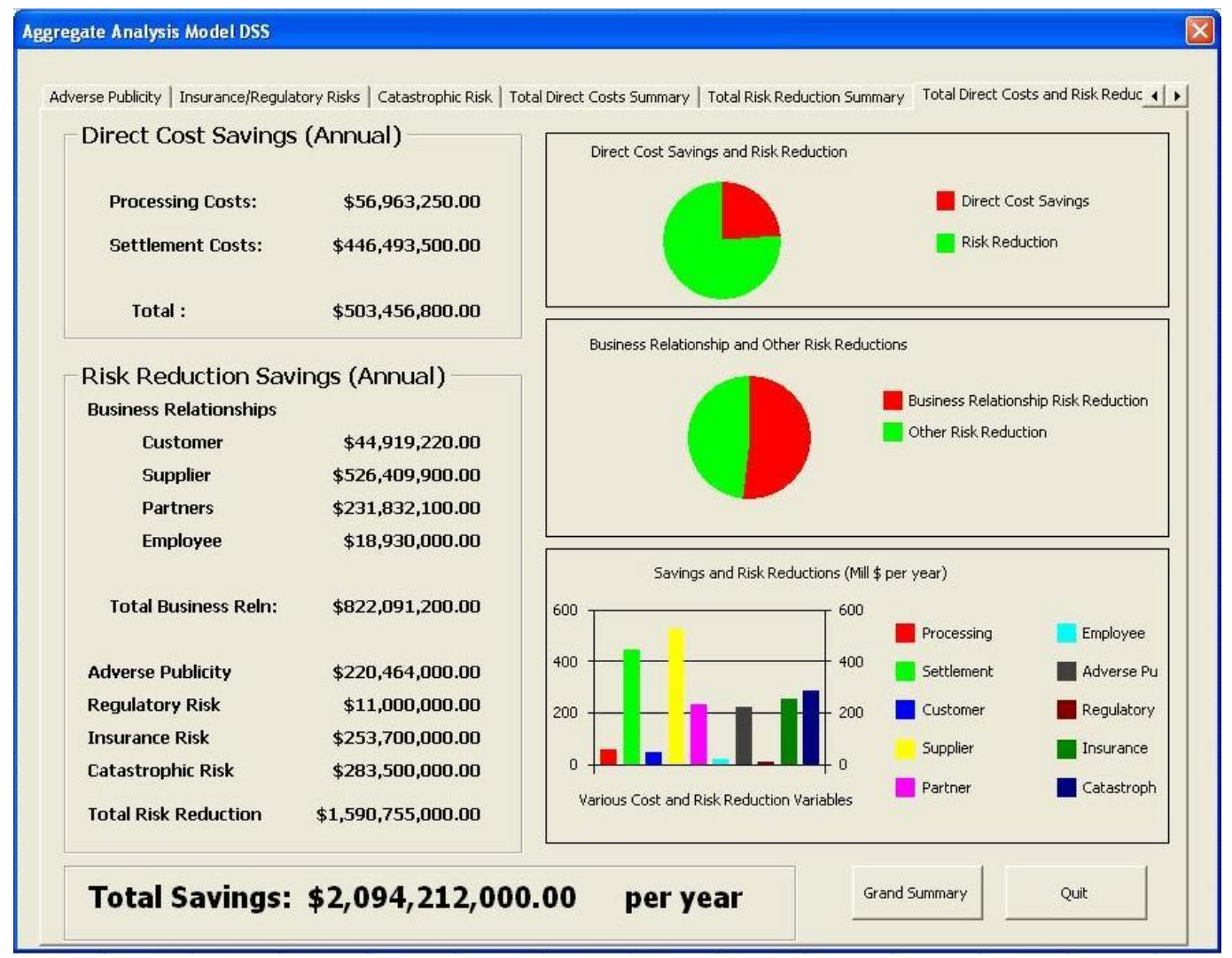

Figure 5: A Screenshot From AA-DSS: Summary Of Total Cost Savings

\section{THE CASE ANALYSIS (CA) MODEL AND CA-DSS}

The case analysis model focuses on an individual case, allowing the user to determine the best resolution mode, i.e. litigation vs. ADR, for a given case. The key element of the analysis is the inclusion of soft costs in the payoff analysis. A decision tree, as shown in Figure 6, is drawn for each case. Figure 8 shows a screenshot of the decision tree created by the CA-DSS. The expected value of litigation vs. ADR are displayed and the suggested decision is displayed. The user can use this model to see how sensitive the payoffs for various are with respect to win and loss probabilities. In the CA model, we make use of fuzzy logic, MCMC simulations, knowledgebase and a database to help the user estimate the probabilities of winning (losing) and to estimate the dollar values of various hard and soft costs. We elaborate on the method of quantifying these probabilities next.

\subsection{Estimating Probabilities Of Winning (Losing)}

The model recognizes the difficulties involved in quantifying probabilities of win (loss). We propose four different methods for quantifying these probabilities - (1) Crisp, (2) Fuzzy-Type-I, (3) Fuzzy-Type-II and (4) FuzzyType-III. The Crisp method allows the user to enter an input between 0 and 1. In the Fuzzy-Type-I method, the user is asked to choose from one of seven options - Extremely Unlikely, Unlikely, Somewhat Unlikely, Can't Say, Somewhat Likely, Likely and Extremely Likely as shown in Figure 7(a). In Fuzzy-Type-II method, the user is presented with a menu of the same seven options. However, the user is now allowed to weigh each option by specifying "how sure" they feel about a given option. For example, the user may want to be somewhere between "Very Likey" and "Somewhat Likely" and may be inclined more towards "Very Likely" than towards "Somewhat Likely". In this situation, they can say they are, for instance, 0.8 sure about "Very Likely" and 0.2 sure about "Somewhat Likely". This situation is depicted in Figure 7(b). 


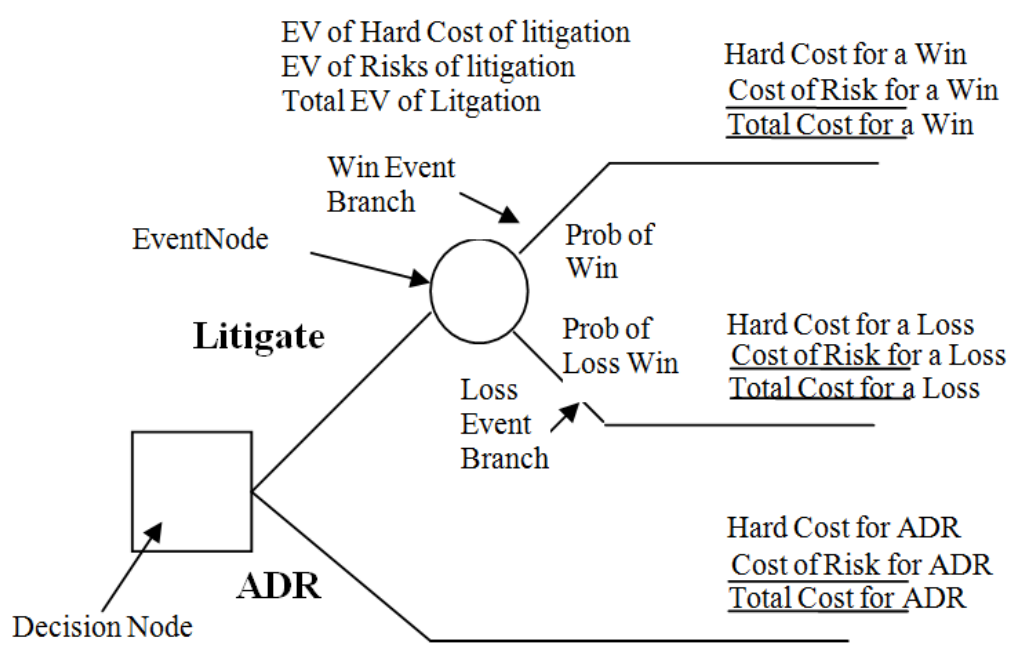

Figure 6: Case Analysis Decision Tree

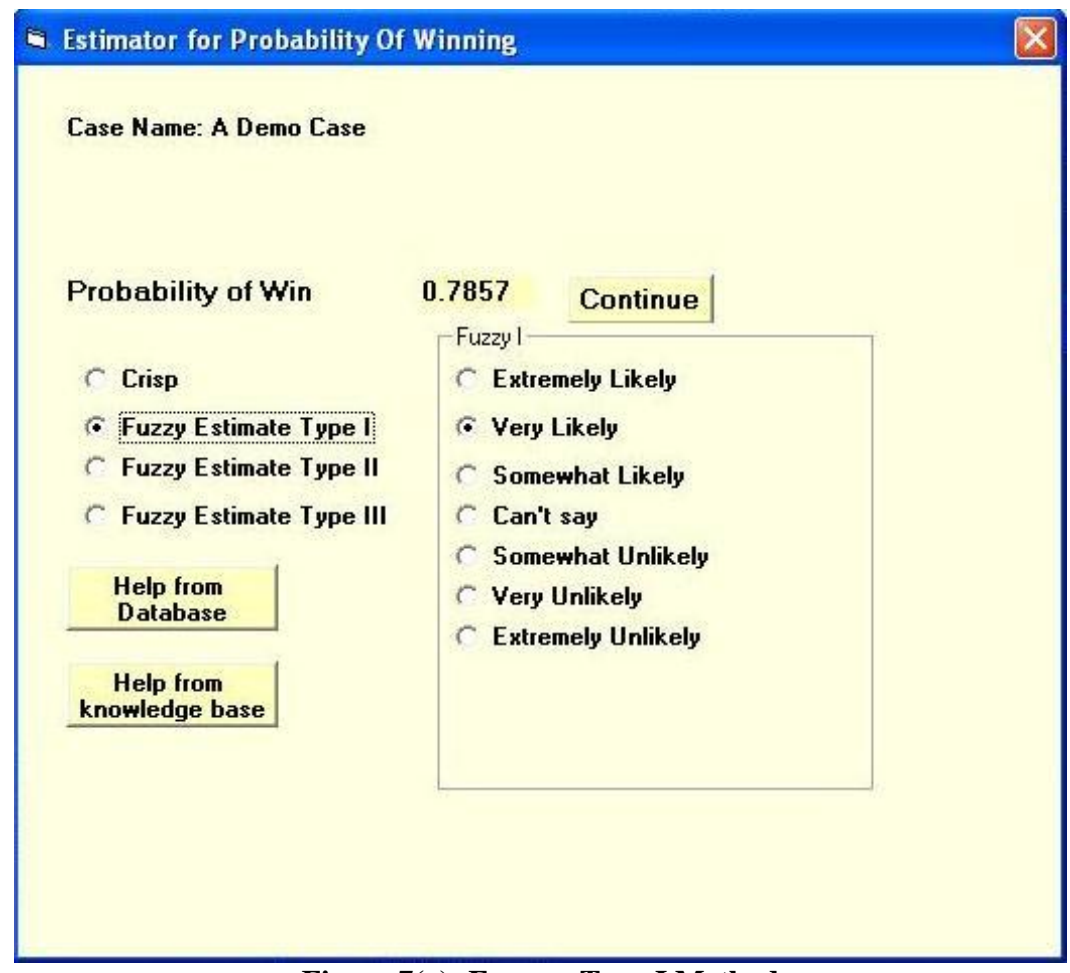

Figure 7(a): Fuzzy - Type I Method 


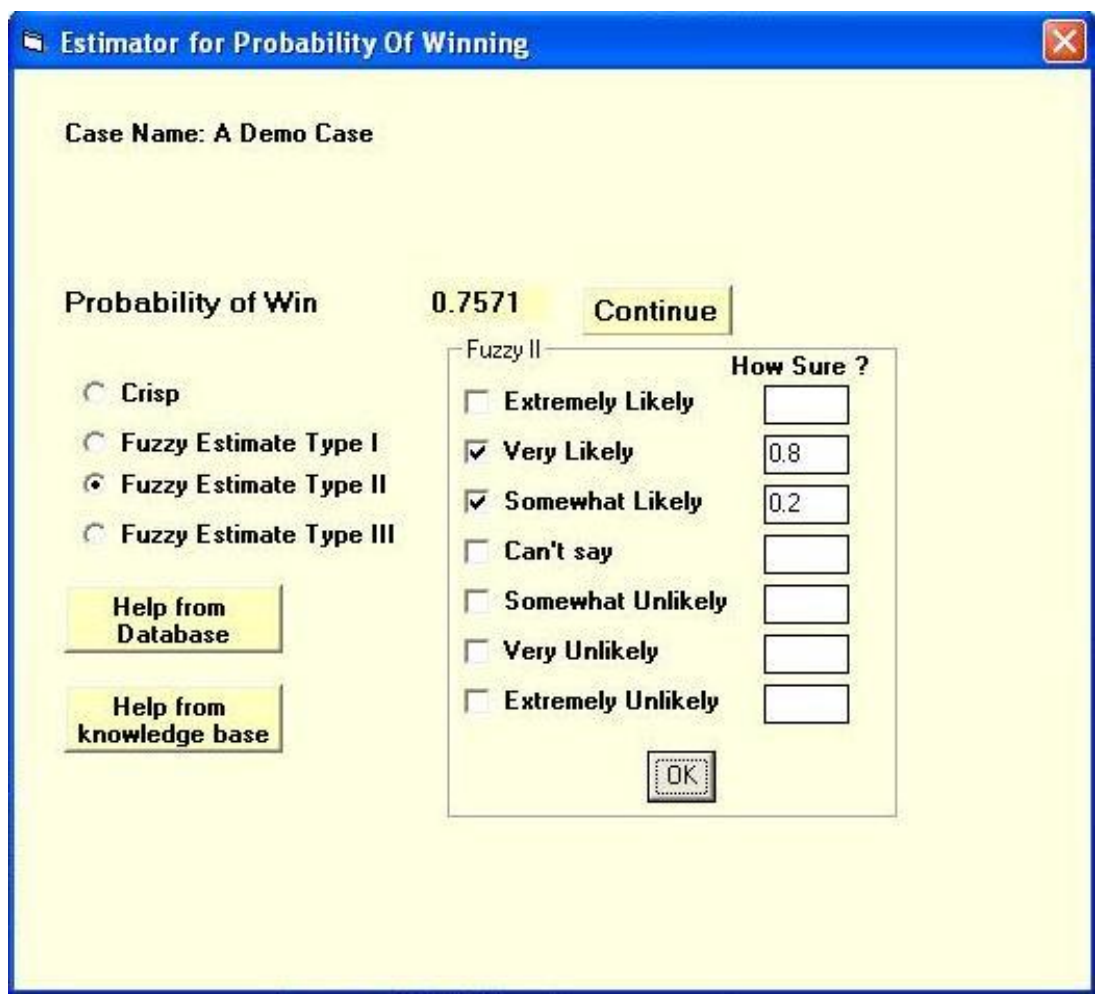

Figure 7(b): Fuzzy - Type II Method

In the Fuzzy-Type-III option, Figure 7(c), the user can specify the most-optimistic, the most-likely and the most pessimistic probability of winning (losing). For example, in Figure 7(c), the most optimistic likelihood for a win is 0.8 , most pessimistic is 0.3 and most likely is 0.6 . MCMC simulation transforms these three numbers into a probability measure between 0 and 1 . For example, in this case, the probability of winning turned out to be 0.565 . With a menu of these four ways of arriving at the probabilities of winning (losing) the user has the options to use which ever method suits them the best without having to guess a number between 0 and 1 . The user can also click on the "Help from Database" and "Help from Knowledgebase" and obtain data from past cases. For example, for a given type of case, past data might reflect the probabilities of winning or losing.

\subsection{Estimating Hard And Soft Costs Of Winning (Losing) And ADR}

On the decision tree, the decision maker can also input the hard and soft costs of winning or losing the case if litigation takes place. The CA-DSS provides wizards for the decision maker to help with these estimates. For example the wizards help break up the estimates into the various components of hard and soft costs outlined in Section 4. For each component, there is a wizard, which allows the user to enter various numbers. On each wizard, to further assist the user in making estimates is help from a database and a knowledge base of past cases. From the database, the user can get information such as past history of cases of similar type and the outcome of those cases and the actual costs involved. From such information the user can estimate the various hard and soft costs. A knowledge base offers deeper insight. For example, it can provide information such as for x percent of cases the hard costs were in a certain range and for $\mathrm{y} \%$ of the cases they were in some other range. Based on this information, the user will be able to make superior estimates. By forcing the user to enter all numbers, the CA model ensures that the often hard-to-measure soft costs are not neglected. 


\section{G. Estimator for Probability of Winning}

Case Name: A Demo Case

Probability of Win

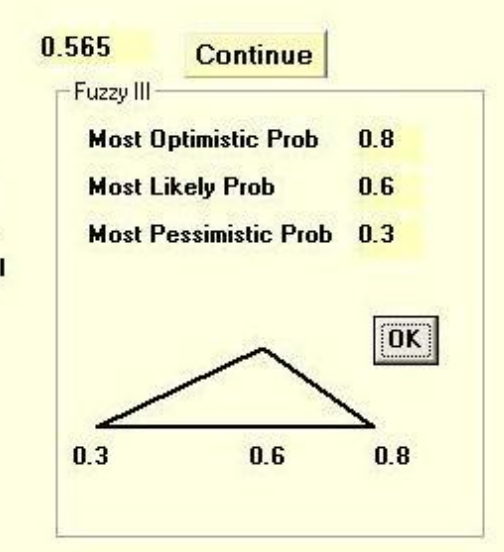

Crisp

Fuzzy Estimate Type I

C Fuzzy Estimate Type II

c Fuzzy Estimate Type III

Help from

Database

Help from

knowledge base

Figure 7(c): Fuzzy - Type III Method

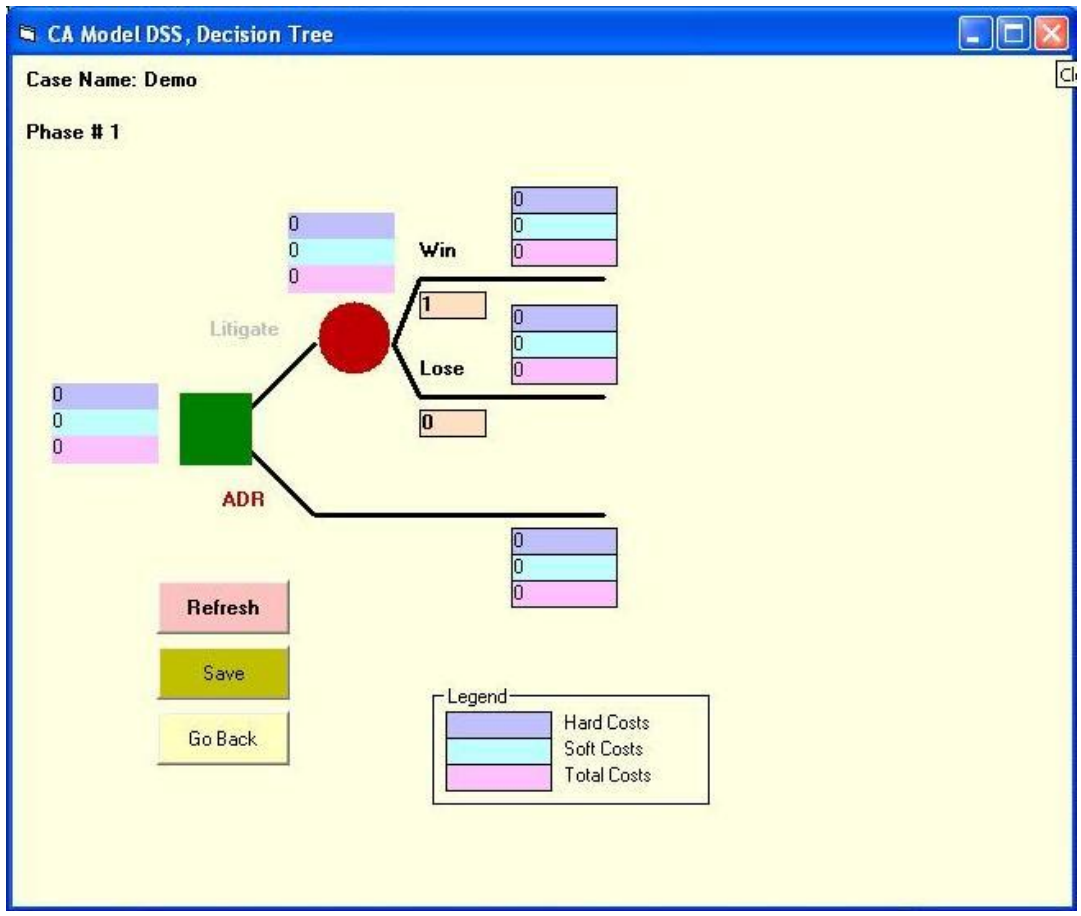

Figure 8: A Screenshot From CA-DSS Showing The Decision Tree 
If the user uses the CA model for each case and makes ADR vs. litigation decision based on the decision tree provided by the CA model, then it is likely that more cases will be subject to ADR options than litigation.

\section{SUMMARY AND CONCLUSIONS}

We note that the litigation environment in the U.S. and the associated economic consequences require sophisticated approaches for gathering decision-relevant information to support key decisions. However, we have found that General Counsel's Offices show a surprising preference to rely solely on "hard costs" that are easily measured, e.g., litigation processing and settlement costs. Surprisingly, no effort is made to factor in the relevance of difficult-to-measure "soft costs" (e.g., adverse reputational effects). We conjecture that measurement challenges have greatly inhibited optimal responses by General Counsel's Offices as well as business managers in resolving business conflicts and disputes. Specifically, easily quantified direct costs (e.g., out-of-pocket expenses related to pursuing and defending against litigation) appear to crowd out more difficult-to-quantify indirect risks and costs (e.g., damaged relationships with customers and potential alliance partners, including reputational harm). We characterize this aversion to gathering decision-relevant information (esp. as it related to soft costs) as a corollary of the Gresham's Law of Measurement ("hard costs tend to crowd out soft costs"), and propose two models at a macroand micro-level respectively to alleviate this measurement problem. We also hypothesize that the benefits of Alternative Dispute Resolution (ADR) strategies may have been muted because of the failure to assess the real magnitude of not-easily-quantified indirect risks and costs that sometimes may pose catastrophic risk to companies and are frequently orders of magnitude more severe than direct costs.

We adopt a two-pronged approach in invoking both a macro-level, aggregate model applying to the entire litigation portfolio as well as a micro-level single litigation case model. Accordingly, we present two models - the Aggregate Analysis (AA) model and the Case Analysis (CA) model for helping the General Counsel's Office, as the primary decision maker, make better decisions about how a new dispute or a conflict must be resolved, i.e., through litigation or through one of the various alternative dispute resolution options such as arbitration, mediation, negotiation etc. A strategic dispute resolution (SDR) strategy is proposed wherein it is encouraged that more cases be resolved through ADR. It is argued that the General Counsel's Office might be overlooking some of the negative impacts, qualitatively speaking, of going through a litigation process. The negative impact factors in risks accruing from the litigation process in terms of things like loss of brand image or loss of business alliance and such.

The AA model provides the decision maker to study the effect of broadly implementing an SDR strategy. The savings in costs, both hard and soft, are provided by the model. An interactive DSS with a graphic user interface is then designed and implemented which allows the user to interactively manipulate the various input values and see their effect on cost savings through instant graphs. The CA model gives the decision maker a decision tree tool by which to analyze the payoff from the various dispute resolution options of litigation vs. ADR. The DSS has a database and a knowledgebase built in which provides the user with past case histories and past trends which helps the user with more intelligent estimates of win (loss) probabilities and the costs involved in the litigation and ADR processes. Both hard and soft costs are estimated in the CA model to give the General Counsel's Office, as the primary decision maker, a better tool for cost/benefit analysis. By providing the means to gather decision-relevant information, including about difficult-to-measure soft costs, we have effectively minimized the "decision making risk" for General Counsel's Offices. In the process, we have also furnished some creative ways to combat the otherwise pernicious effects and outcomes of the so-called Gresham's Law of Measurement and reach more informed assessments to support litigation risk management decisions.

\section{AUTHOR INFORMATION}

Dr. Anurag Agarwal is an Associate Professor of Information Systems and Decision Sciences in the College of Business at University of South Florida, Sarasota-Manatee. He earned a Bachelor's degree from Indian Institute of Technology, Roorkee, India, an MBA from University of Wisconsin, La Crosse and a Ph.D. degree in Management Information Systems from The Ohio State University. He teaches a variety of courses in information systems, decision support systems, statistics and operations management. His research interests are in decision support systems, artificial intelligence, operations research and mathematical modeling. He has published his research in a variety of journals. E-mail: agarwala@ sar.usf.edu 
Dr. Sridhar Ramamoorti is an Associate Professor of Accountancy at Kennesaw State University. He earned a Bachelor's degree from Bombay University, India, and holds MAcc. and Ph.D. (Quantitative Psychology) degrees from The Ohio State University. Dr. Ramamoorti's unique, academic-practitioner background includes being a University of Illinois Accountancy Faculty member, a principal with Arthur Andersen, Sarbanes Oxley Advisor for Ernst \& Young, and a Corporate Governance partner with Grant Thornton. A prolific, international author and speaker, Sri has made presentations in the USA, Brazil, Canada, France, India, Japan, the Netherlands, Qatar, South Africa, Spain, Turkey, and the United Arab Emirates. E-mail: sriram@kennesaw.edu

Dr. Vaidyanathan Jayaraman is an Associate Professor in Dept. of Management, School of Business Administration, University of Miami. He received his M.S in Mathematics, M.B.A. in Management/Information Systems from University of Akron, and M.S. in Operations Research and a Ph.D. in Operations and Supply Chain Management from The Ohio State University. He has received several awards both in teaching and research. His primary research interests are in Strategic design and Management of Supply Chains and Sustainable Value Chain Systems and Service Operations Management (Buyer-Supplier Relationships and Knowledge Process Outsourcing in emerging markets). He has published extensively in several journals. E-mail: vaidy@ miami.edu

\section{REFERENCES}

1. Badredline, A. 2006. Linguistic fuzzy-logic game theory. The Journal of Conflict Resolution. 50, 28-58.

2. Brown, H. and Marriott, A. 1999. ADR Principles and Practice, $2^{\text {nd }}$ edition, Sweet and Maxwell, London.

3. Cheung, S. and Suen, H.C. 2002. A multi-attribute utility model for dispute resolution strategy selection. Construction Management and Economics. 20, 557-568.

4. Hamouda, L., Kilgour, M. and Hipel, K.W. 2004. Strength of preference in the graph model for conflict resolution. Group Decision and Negotiation. 13, 449-456.

5. Lootsma, F.A. 1989. Conflict resolution via pairwise comparison of concessions. European Journal of Operational Research. 40, 109-116.

6. $\quad$ Pawlak, Z. 2005. Some remarks on conflict analysis. European Journal of Operational Research. 166, 649654.

7. Cravens, K., Oliver, E. and Ramamoorti, S. (2003). The Reputation Index: Measuring and Managing Corporate Reputation. European Management Journal, 21(2), 201-212.

8. Roberto, M.A., Bohmer, R.M.J. and Edmondson, A.C. 2006. Facing Ambiguous Threats. Harvard Business Review. November: 106-113.

9. Shavell, S. 1995. Alternative dispute resolution: An economic analysis. Journal of Legal Studies. 24(1), 123.

10. Takahashi, M.A., Fraser, N. M. and Hipel, K.W. 1984. A procedure for analyzing hypergames. European Journal of Operational Research. 18, 111-122.

11. Zeleznikow, J. 2000. Building Decision Support Systems in Discretionary Legal Domains. International Review of Law Computers \& Technology. 14, 341-356.

12. http://www.nadr.co.uk/background/contrast.php

13. $\quad$ http://www.usatoday.com/news/nation/2001/08/14/walmart-usat.htm 


\section{NOTES}

